WHeN in 1947 I went to Nigeria to try to start that country's first university at Ibadan, I had a capital sum of $£ 1.5$ million provided by the British government for buildings. Tough negotiations persuaded the Nigerian government to increase its proposed annual grant (to meet other costs) from $£ 60,000$ to $£ 100,000$. These sums soon proved to be inadequate and larger amounts eventually became available; but until oil was discovered in the country we were always short of money.

I therefore find it hard to be as sympathetic as I should to the universities of the UK in their present financial position. After all, their grant from the goverment has increased by some 200 times in 25 years. I think that it is right that their expenditure should be carefully scrutinised.

There is growing concern about student numbers and the entry into different faculties. Politicians and others have suggested that money should not be spent on training specialists for jobs which do not exist, especially when the training is particularly expensive. Unfortunately, attempts to relate graduates to jobs have seldom been successful. Thus in medicine we had the Willink and Goodenough committees, which restricted the growth of medical schools at a time when expansion was later shown to have been needed.

Yet this should have been a comparatively easy exercise for, notwithstanding the egregious mistakes of our demographers (who in 1945 estimated that by 1965 Britain's population would fall by 4 millions, though in fact it increased by about the same number), the number of patients and their diseases remains fairly constant year by year. Few people would suggest at present reducing our intake of medical students, even though it costs the taxpayer something like $£ 100,000$ to train a qualified doctor.

Universities claim, with some justification, that they need to maintain a good academic balance, and that one faculty should not grow so rapidly that it overshadows the others. Some even believe that there is an ideal ratio for the number of students in different faculties. I remember hearing Lord Hailsham, when in charge of higher education some twelve years ago, deploring the insistence of universities on enlarging their faculties of law and social science, even when there was no increased demand for lawyers and social scientists, as a condition for producing the larger number of scientists for whom there seemed, at that time, to be a demand. Sadly,

\section{Lowering costs in higher education}

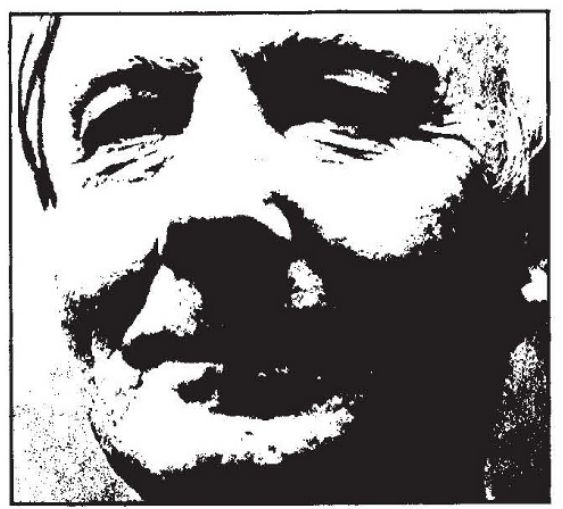

KENNETH MELLANBY

some of the increased number of scientists found, after graduation, that they were also unwanted. To estimate future manpower needs is clearly difficult.

When funds are plentiful, there is less demand to regulate entries into expensive courses. We are rightly proud of our high academic standards, and resist attempts to lower them. Nevertheless more thought could be given to reducing costs. If we are admitted to a British hospital, we will probably be attended by a doctor who qualified in India or Pakistan. Some may arrive with inadequate English and others (like, unfortunately, some of our own graduates) may be incompetent. But the majority carry out their duties admirably. Yet the cost of their training was only a fraction of that incurred in the UK. It is difficult not to believe that there is some room for economy, even in medicine.

Veterinary training is not quite so expensive, but costs probably amount to about $£ 50.000$ a graduate. This is justified because the veterinary sur- geon makes an important contribution to food prcduction by his care of farm animals. The present trend will dcuble the number of vets in practice in Britain within the next 20 years. It is right to wonder whether this is wise or prudent. At present more than half of veterinary practice is devoted to what are, rather charmingly, called 'companion animals'. These are pets, dogs, cats and also horses and ponies. Now it would be wrong to suggest that these are unimportant. They bring pleasure to many, and companionship and solace to elderly and lonely people. They need to be cared for.

But it is surprising to find that some 6 million dogs, rather fewer cats and 250,000 horses take up more veterinary time than do 50 million farm animals (cattle, sheep and pigs) and nearly 150 million poultry. If our farm animals are receiving anything like proper attention, some companion animals would seem to be overprivileged, particularly as experience suggests that the only contact many dogs and cats have with a vet is to be put down when they are old or unwanted. If, as many expect, the number of intensively kept farm animals falls substantially as supplies of cheap imported feeding stuffs dry up, will we need as many vets for agriculture? Can we afford them for our pets?

It is generally agreed that all our school leavers able to profit from higher education should have the opportunity to do so, but need this be so expensive? Can we really justify a staff-student ratio three or more times as high as that obtaining in many other countries? Has enough attention been given to devising more general-and less expensive-courses? We often hear that change in science-based subjects is so rapid that every practitioner will have to be retrained at least once every 10 years. Are we devoting enough of our scarce resources to retraining, and might it not be better to reduce the scale of that given initially?

No doubt these problems are in many people's minds, but so far changes have generally raised rather than lowered academic costs. Perhaps the financial crisis will ensure that action is taken to reduce waste and still to maintain standards. as an important step towards the 375 foot radio dish planned for the observatory's Meiford site in Wales, some $85 \mathrm{~km}$ away.

The new facility, which will use three existing radio dishes that are capable of working down to centimetre wavelengths, will also increase the inter- ferometer baseline from 20 to $85 \mathrm{~km}$ by adding a new $25 \mathrm{~m}$ low cost dish in Montgomeryshire. The whole system will be centrally controlled from Jodrell's new interferometer control room.

"The new facility will not replace the 'big dish'-it simply makes the best use of the equipment and expertise we already have", says Sir Bernard. As for the 'big dish', he still hopes to finance the 375-footer at Meifod. Plans had to be dropped two years or so ago because the international tenders were far higher than expected: $£ 16$ million as against an estimated $£ 10$ million. 